\title{
Tracing the origins and signatures of selection of antifolate resistance in island populations of Plasmodium falciparum
}

\author{
Patrícia Salgueiro1, José L Vicente1, Conceição Ferreira², Vânia Teófilo, André Galvão', Virgílio E do Rosário1, \\ Pedro Cravo ${ }^{1}$ and João Pinto*1
}

\begin{abstract}
Background: Resistance of the malaria parasite Plasmodium falciparum to sulfadoxine-pyrimethamine (SP) has evolved worldwide. In the archipelago of São Tomé and Principe (STP), West Africa, although SP resistance is highly prevalent the drug is still in use in particular circumstances. To address the evolutionary origins of SP resistance in these islands, we genotyped point mutations at $P$. falciparum $d h f r$ and $d h p s$ genes and analysed microsatellites flanking those genes.

Methods: Blood samples were collected in July and December 2004 in three localities of São Tomé Island and one in Principe Island. Species-specific nested-PCR was used to identify P. falciparum infected samples. Subsequently, SNPs at the dhfr and dhps genes were identified through PCR-RFLP. Isolates were also analysed for three microsatellite loci flanking the $d$ hfr gene, three loci flanking dhps and four loci located at putative neutral genomic regions.

Results: An increase of resistance-associated mutations at dhfr and dhps was observed, in particular for the dhfr/dhps quintuple mutant, associated with clinical SP failure. Analysis of flanking microsatellites suggests multiple independent introductions for dhfr and dhps mutant haplotypes, possibly from West Africa. A reduced genetic diversity and increased differentiation at flanking microsatellites when compared to neutral loci is consistent with a selective sweep for resistant alleles at both loci.

Conclusions: This study provides additional evidence for the crucial role of gene flow and drug selective pressures in the rapid spread of SP resistance in P. falciparum populations, from only a few mutation events giving rise to resistanceassociated mutants. It also highlights the importance of human migration in the spread of drug resistant malaria parasites, as the distance between the islands and mainland is not consistent with mosquito-mediated parasite dispersal.
\end{abstract}

\section{Background}

Resistance to virtually all classes of antimalarial drugs has evolved in natural populations of Plasmodium falciparum, the human malaria parasite species responsible for the great majority of malaria-attributed child mortality and morbidity. Resistance to chloroquine (CQ) is prevalent in nearly all malaria-endemic regions, leading to the discontinued use of this drug globally. Resistance to sulfadoxine-pyrimethamine (SP), an affordable and widely available alternative to $\mathrm{CQ}$, has also spread rapidly.

\footnotetext{
* Correspondence: jpinto@ihmt.unl.pt

1 UEl Malária \& UEI Biologia Molecular, Centro de Malária e outras Doenças Tropicais, Instituto de Higiene e Medicina Tropical, Universidade Nova de Lisboa. Rua da Junqueira 100, 1349-008 Lisboa, Portugal Full list of author information is available at the end of the article
}

Furthermore, therapeutic failure to the most recent arteminisin combination therapies (ACTs) has been reported in Southeast Asia [1].

Mutations in genes encoding dihydrofolate reductase $(d h f r)$ and dihydropteroate synthase (dhps) enzymes of the parasite's folate pathway are associated with resistance to pyrimethamine and sulfadoxine, respectively [2,3]. Point mutations at codons 51, 59 and 108 of $d h f r$, operate synergistically to enhance resistance to pyrimethamine. The level of resistance is much higher in a triple mutant N51I/C59R/S108N than in a single or double mutant. Likewise, mutations at codons 437 and 540 of dhps increase the level of resistance to sulfadoxine, with the double mutant A437G/K540E showing the high- 
est level of resistance. Considering the two genes together, the quintuple mutant N51I/C59R/S108N/ A437G/K540E accounts for clinical failure of SP [4].

As a result of the increased levels of resistance, SP has been gradually removed from malaria control programs worldwide. Nevertheless, selective pressure for SP-resistant mutants persists, given the continued use of SP in specific situations. Owing to its safety, SP is still recommended for intermittent preventive therapy (IPT) in pregnant women and children, even in regions where SP efficacy for treatment of severe malaria is compromised [5]. Also, an antifolate compound similar to SP, trimethoprim-sulphamethoxazole, is suggested to prevent opportunistic infections in HIV-infected patients in developing countries [6]. Therefore, the origin and evolution of SP resistance remains a topic of both evolutionary and epidemiological relevance. Furthermore, insights on resistance to SP may also contribute to a better understanding of the evolutionary dynamics of resistance to other drugs.

Roper et al. [7] presented evidence suggesting that the dhfr triple mutant N51I/C59R/S108N occurring in South Africa had a common ancestry with the Southeast Asian triple mutant. Subsequent studies have shown that this haplotype has spread throughout the African continent and only very few local/regional haplotype variants of African origin have been so far reported [8-12]. These studies demonstrate also relatively few independent origins of double mutants at the dhfr gene, though greater variation can be found in single mutants. Fewer studies are available for the dhps gene but a recent continentwide study of Sub-Saharan African P. falciparum populations has shown that mutant dhps alleles have originated from five independent geographically delimited ancestral lineages: three for single mutants (A437G) and two for double mutants (A437G/K540E) [13]. Collectively, the above findings highlight that limited mutation events followed by extensive gene flow have driven SP resistance in P. falciparum populations worldwide. Interestingly, this appears not to be the case in Plasmodium vivax for which resistance-associated mutations at the $d h f r$ locus have arisen from multiple independent mutation events in Southeast Asia [14].

Selection of mutant parasites through drug pressure is also a key factor for the rapid spread of SP resistanceassociated alleles. In a situation of marked selective pressure acting on advantageous mutations at a locus, genetic diversity tends to decrease and linkage disequilibrium increases in the surrounding regions through genetic hitchhiking. This process, also known as selective sweep, can be detected by the analysis of putatively neutral genetic markers flanking the locus under selection at increasing distances [15]. Using this approach, selective sweeps of resistant dhfr and dhps alleles have been described for $P$. falciparum samples from Southeast Asia, Africa and South America [10,16-18].

Until recently, CQ and SP remained respectively the $1^{\text {st }}$ and $2^{\text {nd }}$ line therapeutic lines for malaria in the archipelago of São Tomé and Principe (STP). However, the increasing levels of both in vivo and in vitro resistance to these antimalarials coupled with molecular surveys pointing to high levels of resistance-associated mutations [19-22], led to a change in the malaria therapeutic regime. In the case of SP resistance genes, two reports point to an increase of triple mutants N51I/C59R/S108N for the $d h f r$ gene [21,22]. In 2004, the STP government approved a new antimalarial drug regime with artemisinin-based combination therapies [23]. Since then STP has become one of the few countries where the malaria burden was reduced by $50 \%$ or more between 2000 and 2006-2007, in line with WHO targets. Presently, SP is used in the islands only for IPT during pregnancy. In 2007 the rate of IPT use by pregnant women reached $76 \%$ [23], indicating that selective pressure for SP-resistant mutants is still present in STP.

In this context, the aims of the present study were: i) to obtain a contemporary snapshot on the prevalence of point mutations in the pfdhfr and pfdhps genes in natural $P$. falciparum populations of STP; and ii) to investigate the origin and evolutionary dynamics of these mutations, by analysing microsatellite loci flanking these genes. Results are interpreted with respect to the main evolutionary forces driving SP resistance in the local $P$. falciparum populations, in light of the fact that these are island populations, in which gene flow is likely to be more restricted than in the mainland.

\section{Methods}

\section{Study sites and sampling}

The Democratic Republic of São Tomé and Príncipe (STP) is located in the Gulf of Guinea, $c a .240 \mathrm{~km}$ off the coast of Gabon, West Africa. It comprises two main islands: São Tomé $\left(859 \mathrm{~km}^{2}\right)$ and Príncipe $\left(142 \mathrm{~km}^{2}\right)$, with most of the 150,000 residents living in São Tomé. Malaria reaches meso-hyperendemic levels and all four human Plasmodium species are present in both islands, but with large predominance of $P$. falciparum infections [24].

Blood samples were collected in July 2004 by finger prick from children up to nine years-old, from three localities of São Tomé - Neves $\left(0^{\circ} 22^{\prime} \mathrm{N} ; 6^{\circ} 32^{\prime} \mathrm{E}\right)$, Ribeira Afonso $\left(0^{\circ} 12^{\prime} \mathrm{N} ; 6^{\circ} 43^{\prime} \mathrm{E}\right)$ and Angolares $\left(0^{\circ} 4^{\prime} \mathrm{N} ; 6^{\circ} 32^{\prime} \mathrm{E}\right)$, and one from Príncipe - Rua dos Trabalhadores $\left(1^{\circ} 38^{\prime} \mathrm{N}\right.$; $7^{\circ} 25^{\prime} \mathrm{E}$ ). Collections were undertaken within the framework of active-case malariological surveys carried out by the Centro Nacional de Endemias, Ministry of Health of STP. Ethical clearance was obtained from the Ministry of Health of STP. Informed consent was obtained by the parents or tutors of the children sampled. The localities 
of Neves and Angolares were sampled a second time, in December 2004. Henceforward, these samples will be referred to as Neves II and Angolares II, respectively. Individual blood samples were spotted onto Whatman No. 4 filter papers and kept dry at room temperature until further processing.

\section{DNA isolation, species identification and genotyping of dhfr and dhps}

Blood spot samples were used to perform DNA extraction by a Chelex protocol [25]. Each DNA sample was then used in a nested-PCR reaction, in order to identify the presence of $P$. falciparum according to Snounou et al. [26]. Using the PCR-RFLP method described by Duraisingh et al. [27], parasite DNA was checked for Single Nucleotide Polymorphisms (SNPs) at codons 51, 59 and 108 of the dhfr gene and at codons 437 and 540 of the dhps gene.

\section{Genotyping of microsatellite loci}

In order to determine the evolutionary origins of $d h f r$ and dhps haplotypes, we explored polymorphic microsatellites flanking both genes, located $0.3 \mathrm{~kb}, 4.4 \mathrm{~kb}$ and $5.3 \mathrm{~kb}$ upstream of codon 108 of $d h f r$ (chromosome 4) and 0.8 $\mathrm{kb}, 4.3 \mathrm{~kb}$ and $7.7 \mathrm{~kb}$ downstream from codon 437 of dhps (chromosome 8). A semi-nested PCR was performed for each locus using the primers originally described by Roper et al. [28] but with the primer modifications (i.e. nucleotide extensions) suggested by Ndiaye et al. [11] for the $d h f r$ flanking microsatellites, to minimise stuttering. PCR reactions and cycling conditions were as described by Roper et al. [28]. Amplified fragments were separated by capillary electrophoresis in an automatic sequencer (ABI 3730, Applied Biosystems) at the Yale University DNA Analysis Facility on Science Hill. Allele sizes were scored using the software GeneMarker (SoftGenetics). As a reference, we have used the Southeast Asian P. falciparum $\mathrm{K} 1$ laboratory strain. This strain has a known microsatellite profile for the loci used that differs from the widespread $d h f r$ triple mutant lineage of Asian origin (Roper C., pers. comm.). At microsatellites flanking the dhps gene, the allelic composition of the K1 strain matches that of the East African dhps double mutant A437G/K540E haplotype lineage SGE 1 [13].

As suggested by McCollum et al. [10], we considered a $d h f r$ or dhps allele sensitive if it lacked drug resistanceassociated mutations within the coding region. The term "haplotype" refers to a particular multilocus genotype composed by the resistance-specific polymorphic locus and the corresponding flanking microsatellite loci. Haplotypes were differentiated if they contained one or more allelic change across the loci. For haplotype reconstruction, we excluded all samples that failed to amplify in any of the loci or that generated multiple peaks [28], in order to avoid incorrect haplotype calling. For the remaining analyses, if multiple peaks (alleles) were detected at any locus, only the predominant allele (i.e. the peak with the highest amplification intensity) was chosen as the representative haplotype.

In order to obtain a measure of genetic variation and linkage disequilibrium at putative neutral regions, we genotyped further four microsatellite loci: TAA81 (chr. 5), PfPK2 (chr. 12), TAA109 and TAA87 (chr. 6). Primer sequences and PCR conditions are described in $[29,30]$. PCR products were separated and scored as described above. For each microsatellite locus, in cases where multiple peaks were present, only the value of the highest peak was scored. The results derived from these neutral markers were put in context with the patterns observed in the microsatellites surrounding the $d h f r$ and $d h p s$ genes.

\section{Statistical analysis}

We assessed allelic richness $\left(R_{s}\right)$, a measure of the number of alleles independent of sample size, using FSTAT v. 2.9.3 [31]. The Microsoft ${ }^{\circ}$ Office Excel Microsatellite tool kit [32] was used to obtain allele frequencies for expected heterozygosity $\left(H_{e}\right)$ calculations. We calculated $H_{e}$ as in Anderson et al. [33]. Genetic differentiation per locus in the total population sample was measured using an unbiased estimator of $F_{S T}$ [34] available in FSTAT. Linkage disequilibrium (LD) was computed by exact tests of LD available in GENEPOP v. 4.0 [35]. Initially, we compared sulfadoxine-sensitive and resistant genotypes at the dhps locus by defining subsamples as wild-type (or sensitive), single mutant (A437G) or double mutant (A437G/ K540E). This approach was not implemented for the pyrimethamine resistance-associated $d h f r$ gene, because we did not detect any wild-type individuals and the number of single mutants was extremely low. Therefore, we could only compare triple mutants (N51I/C59R/S108N) with double mutants (N51I/S108N). Corrections of the nominal significance value $(\alpha=0.05)$ to account for multiple testing were performed by a sequential Bonferroni procedure [36].

\section{Results}

\section{Point mutations at dhfr and dhps loci}

Of the 934 blood samples analysed, approximately one third $(N=326)$ were positive for $P$. falciparum. Table 1 describes the prevalence of wild-type, mutant and mixed alleles infections for both $d h f r$ and $d h p s$ genes, as well as the corresponding genotypes. Allelic frequencies were overall similar when comparing different sampling sites and years.

For $d h f r$, pyrimethamine resistance-associated mutations N51I and S108N were extremely predominant (96\%) and $60 \%$ of the samples harboured the C59R muta- 
Table 1: Allele and genotype frequencies of $d h f r$ and dhps genes in Plasmodium falciparum of STP

\begin{tabular}{|c|c|c|c|c|c|c|c|c|c|c|c|c|c|c|c|}
\hline \multirow[t]{3}{*}{ Island } & \multirow[t]{3}{*}{ Site } & \multicolumn{6}{|c|}{ Mutations } & \multicolumn{8}{|c|}{ Genotypes } \\
\hline & & & \multicolumn{3}{|c|}{ dhfr } & \multicolumn{2}{|c|}{ dhps } & \multicolumn{4}{|c|}{ dhfr } & \multicolumn{3}{|c|}{ dhps } & \multirow{2}{*}{$\begin{array}{l}\text { dhfr/dhps } \\
\text { quintuple }\end{array}$} \\
\hline & & & N51I & C59R & S108N & A437G & K540E & WT & single & double & triple & WT & single & double & \\
\hline \multirow[t]{4}{*}{ Príncipe } & $\begin{array}{l}\text { Rua dos } \\
\text { Trabalhadores }\end{array}$ & wild type & 0.00 & 0.43 & 0.00 & 0.00 & 0.88 & & & & & & & & \\
\hline & & mutant & 1.00 & 0.57 & 1.00 & 0.88 & 0.13 & 0.00 & 0.00 & 0.50 & 0.50 & 0.00 & 0.88 & 0.13 & 0.00 \\
\hline & & mixed & 0.00 & 0.00 & 0.00 & 0.13 & 0.00 & & & & & & & & \\
\hline & & $N$ & 8 & 7 & 9 & 8 & 8 & & & 6 & & & 8 & & 5 \\
\hline \multirow[t]{20}{*}{ S. Tomé } & Ribeira Afonso & wild type & 0.00 & 0.36 & 0.00 & 0.05 & 0.90 & & & & & & & & \\
\hline & & mutant & 0.97 & 0.56 & 0.97 & 0.82 & 0.05 & 0.00 & 0.00 & 0.32 & 0.68 & 0.05 & 0.86 & 0.10 & 0.18 \\
\hline & & mixed & 0.03 & 0.08 & 0.03 & 0.14 & 0.05 & & & & & & & & \\
\hline & & $N$ & 29 & 25 & 29 & 22 & 21 & & & 19 & & & 21 & & 11 \\
\hline & Neves & wild type & 0.08 & 0.48 & 0.00 & 0.23 & 1.00 & & & & & & & & \\
\hline & & mutant & 0.89 & 0.44 & 1.00 & 0.67 & 0.00 & 0.00 & 0.00 & 0.55 & 0.45 & 0.23 & 0.77 & 0.00 & 0.00 \\
\hline & & mixed & 0.03 & 0.07 & 0.00 & 0.10 & 0.00 & & & & & & & & \\
\hline & & $N$ & 37 & 27 & 31 & 30 & 32 & & & 22 & & & 30 & & 18 \\
\hline & Neves II & wild type & 0.00 & 0.39 & 0.05 & 0.11 & 0.98 & & & & & & & & \\
\hline & & mutant & 0.96 & 0.57 & 0.93 & 0.80 & 0.00 & 0.00 & 0.00 & 0.40 & 0.60 & 0.10 & 0.88 & 0.02 & 0.00 \\
\hline & & mixed & 0.04 & 0.04 & 0.01 & 0.09 & 0.02 & & & & & & & & \\
\hline & & $N$ & 73 & 46 & 76 & 64 & 60 & & & 40 & & & 60 & & 30 \\
\hline & Angolares & wild type & 0.02 & 0.30 & 0.00 & 0.18 & 0.84 & & & & & & & & \\
\hline & & mutant & 0.98 & 0.60 & 1.00 & 0.80 & 0.09 & 0.00 & 0.03 & 0.29 & 0.66 & 0.18 & 0.66 & 0.16 & 0.09 \\
\hline & & mixed & 0.00 & 0.10 & 0.00 & 0.02 & 0.07 & & & & & & & & \\
\hline & & $N$ & 41 & 50 & 47 & 44 & 45 & & & 38 & & & 44 & & 33 \\
\hline & Angolares II & wild type & 0.00 & 0.18 & 0.03 & 0.07 & 0.78 & & & & & & & & \\
\hline & & mutant & 1.00 & 0.73 & 0.93 & 0.89 & 0.21 & 0.00 & 0.00 & 0.20 & 0.80 & 0.07 & 0.71 & 0.22 & 0.19 \\
\hline & & mixed & 0.00 & 0.08 & 0.04 & 0.04 & 0.02 & & & & & & & & \\
\hline & & $N$ & 63 & 60 & 71 & 55 & 58 & & & 50 & & & 55 & & 32 \\
\hline \multirow[t]{4}{*}{ STP } & All samples & wild type & 0.02 & 0.32 & 0.02 & 0.12 & 0.89 & & & & & & & & \\
\hline & & mutant & 0.96 & 0.60 & 0.96 & 0.81 & 0.08 & 0.00 & 0.01 & 0.33 & 0.66 & 0.12 & 0.78 & 0.11 & 0.09 \\
\hline & & mixed & 0.02 & 0.07 & 0.02 & 0.07 & 0.03 & & & & & & & & \\
\hline & & $N$ & 251 & 215 & 263 & 223 & 224 & & & 175 & & & 218 & & 129 \\
\hline
\end{tabular}

$N$ : total number of alleles or genotypes 
Table 3: dhps point mutations and their respective microsatellite haplotypes in allele size

\begin{tabular}{|c|c|c|c|c|c|}
\hline \multirow[t]{2}{*}{ Haplotype } & \multirow[t]{2}{*}{ Point mutations } & \multicolumn{3}{|c|}{ Allele size (basepairs) } & \multirow[t]{2}{*}{$N$} \\
\hline & & Locus 0.8 kb & Locus $4.3 \mathrm{~kb}$ & Locus 7.7 kb & \\
\hline K1 & A437G & 131 & 103 & 108 & - \\
\hline $\mathrm{H} 1$ & A437G & 117 & 105 & 104 & 1 \\
\hline $\mathrm{H} 2$ & A437G & 117 & 105 & 106 & 1 \\
\hline $\mathrm{H} 3$ & A437G & 117 & 105 & 116 & 1 \\
\hline $\mathrm{H} 4$ & A437G & 117 & 109 & 134 & 1 \\
\hline $\mathrm{H} 5$ & Wild type & 123 & 103 & 110 & 1 \\
\hline H6 & A437G & 123 & 103 & 124 & 1 \\
\hline $\mathrm{H} 7$ & A437G/K540E & 131 & 103 & 108 & 2 \\
\hline $\mathrm{H} 8$ & Wild type & 133 & 117 & 110 & 1 \\
\hline
\end{tabular}

K1: reference isolate (see methods). $N$ : number of isolates with the correspondent haplotype.

tion. No wild-type genotypes were found and only one sample harboured a single mutation. The triple mutant $\mathrm{N} 51 \mathrm{I} / \mathrm{C} 59 \mathrm{R} / \mathrm{S} 108 \mathrm{~N}$ was present in $66 \%$ of the samples. As for dhps, the most frequent point mutation was A437G (81\%). The double dhps mutant A437G/K540E appeared in $11 \%$ of the samples. Eleven $(9 \%)$ of the samples harboured the quintuple dhfr/dhps mutant (N51I/C59R/ S108N/A437G/K540E), which is predictive of clinical resistance to SP [4].

\section{dhfr and dhps haplotype characterization}

Haplotypes were characterized only in samples for which no multiple infections were detected or that had not failed PCR amplification in any of the loci. The frequency of polyclonal infections was high, as expected from the meso-hyperendemic levels of malaria transmission characteristic of STP [24]. Consequently, our sample size was considerably reduced for this analysis, with haplotypes being reconstructed in 23 out of 175 genotyped isolates for $d h f r$ and in 9 out of 218 genotyped isolates for $d h p s$.
For the $d h f r$ gene, we detected five distinct haplotypes classified as $\mathrm{H} 1$ to $\mathrm{H} 5$ according to the allele sizes at the $0.3 \mathrm{~kb}, 4.4 \mathrm{~kb}$ and $5.3 \mathrm{~kb}$ loci and the mutations carried (Table 2). Three of these haplotypes were associated with the triple mutant N51I/C59R/S108N and the two remaining corresponded to double mutants N51I/S108N. Haplotypes $\mathrm{H} 2$ and $\mathrm{H} 3$ had the same microsatellite composition but carried double and triple dhrf mutations, respectively. The most abundant haplotype associated with the triple mutant (H5), consisting of $114 \mathrm{bp} /$ $183 \mathrm{bp} / 210 \mathrm{bp}$ at the $0.3 \mathrm{~kb} / 4.4 \mathrm{~kb} / 5.3 \mathrm{~kb}$ loci respectively, has matching microsatellite sizes with the $P$. falciparum K1 laboratory strain used as a control. We did not find any parasite carrying the wild-type allele at the three point mutations of the $d h f r$ gene, which precluded the identification of haplotypes associated with pyrimethamine sensitive parasites.

Regarding dhps, eight distinct haplotypes were detected and classified as $\mathrm{H} 1$ to $\mathrm{H} 8$ according to allele sizes at 0.8 $\mathrm{kb}$, and $4.3 \mathrm{~kb}$ and $7.7 \mathrm{~kb}$ loci (Table 3 ). Five haplotypes

Table 2: dhfr point mutations and their respective microsatellite haplotypes in allele size

\begin{tabular}{|c|c|c|c|c|c|}
\hline \multirow[t]{2}{*}{ Haplotype } & \multirow[t]{2}{*}{ Point mutations } & \multicolumn{3}{|c|}{ Allele size (basepairs) } & \multirow[t]{2}{*}{$N$} \\
\hline & & Locus 0.3 kb & Locus 4.4 kb & Locus 5.3 kb & \\
\hline K1 & C59R/S108N & 114 & 183 & 210 & - \\
\hline $\mathrm{H} 1$ & $\mathrm{~N} 51 \mathrm{l} / \mathrm{S} 108 \mathrm{~N}$ & 108 & 181 & 210 & 2 \\
\hline $\mathrm{H} 2$ & $\mathrm{~N} 51 \mathrm{l} / \mathrm{S} 108 \mathrm{~N}$ & 108 & 183 & 200 & 10 \\
\hline H3 & N51I/C59R/S108N & 108 & 183 & 200 & 1 \\
\hline $\mathrm{H} 4$ & N51I/C59R/S108N & 108 & 183 & 210 & 1 \\
\hline H5 & N511/C59R/S108N & 114 & 183 & 210 & 9 \\
\hline
\end{tabular}

K1: reference isolate (see methods). $N$ : number of isolates with the correspondent haplotype. 
were associated with the single mutant A437G. The dhps double mutant A437G/K540E was linked to haplotype H7 consisting of $131 \mathrm{bp} / 103 \mathrm{bp} / 108 \mathrm{bp}$ at the $0.8 \mathrm{~kb} / 4.3 \mathrm{~kb} /$ $7.7 \mathrm{~kb}$ loci respectively. This haplotype is an exact match of the K1 control. Two haplotypes, H5 and H8, were associated with wild type alleles.

\section{Genetic variation and linkage disequilibrium}

The effect of SP selection in the P. falciparum population of STP was assessed by examining the levels of genetic diversity, linkage disequilibrium and genetic differentiation in the microsatellite loci flanking the $d h f r$ and dhps genes, in comparison with neutral loci. We expected to observe signatures of selection left by SP pressure in this population [37], namely: i) a reduction in genetic diversity around dhps and $d h f r$, due to a selective sweep; ii) an increased genetic differentiation at the loci under selection; iii) significant LD between loci flanking dhps and $d h f r$ genes.

Overall, genetic diversity estimates at neutral loci $\left(H_{e}=\right.$ 0.82; $\left.R_{s}=6.5 ; N=308\right)$ were higher than at loci flanking $\operatorname{dhfr}\left(H_{e}=0.64 ; R_{s}=4.6 ; N=298\right)$ and $\operatorname{dhps}\left(H_{e}=0.74 ; R_{s}=\right.$ $5,1 ; N=296)$ genes. For neutral loci, a low but significant $F_{S T}$ of $0.016(P<0.001)$ was obtained for the whole sample subdivided according to collection sites, suggesting a relatively shallow substructuring of $P$. falciparum populations among the localities surveyed. Differentiation was however higher at flanking microsatellites, with $F_{S T}$ values of $0.043(P<0.001)$ and $0.027(P<0.001)$ for $d h f r$ and dhps-linked loci, respectively.

In parasites harbouring $d h f r$ resistant alleles (double and triple mutants), microsatellites flanking the $d h f r$ gene had lower genetic variation than neutral loci and loci flanking the dhps gene (Table 4). Also, genetic differentiation was higher at $d h f r$ flanking loci, mainly attributed to loci $0.3 \mathrm{~kb}\left(F_{S T}=0.38\right)$ and $5.3 \mathrm{~kb}\left(F_{S T}=0.57\right)$ when compared to neutral loci $\left(-0.01 \leq F_{S T} \leq 0.02\right)$ or to loci flanking the dhps gene $\left(-0.01 \leq F_{S T} \leq 0.01\right)$. The levels of genetic diversity and differentiation were similar in neutral loci and in loci flanking the dhps gene.

Microsatellite estimates for parasites carrying wildtype or resistance-associated alleles at the dhps loci are shown in Table 5. Mutant parasites, particularly double mutants, presented lower levels of genetic diversity than wild-type ones at flanking loci. Among wild-type alleles, genetic diversity at flanking loci was comparable to that observed for neutral loci. Genetic differentiation was higher at loci that flanked the dhps gene $\left(0.12 \leq F_{S T} \leq\right.$ $0.30)$ when compared to neutral $\left(-0.01 \leq F_{S T} \leq 0.02\right)$ or $d h f r$-linked $\left(0.00 \leq F_{S T} \leq 0.01\right)$ loci.

Exact tests of linkage disequilibrium revealed three significant associations between pairs of microsatellite loci out of 92 tests performed with isolates carrying $d h f r$ dou- ble or triple mutants. Of these, there was a single significant association between loci flanking the $d$ hfr gene (loci $4.4 \mathrm{~kb}$ and $5.3 \mathrm{~kb}$ ) that was found in the sample of double mutants. For the dhps gene, there were 6 significant pairwise associations between microsatellite loci out of 135 tests. These were all detected in the group of single mutants and there was also only a single significant association involving two microsatellites flanking the dhps gene (loci $0.8 \mathrm{~kb}$ and $4.3 \mathrm{~kb}$ ).

\section{Discussion}

When the results of the present study (collections in 2004) are interpreted in light of reports from surveys carried out in 2000 [21] and in 2002 [22], a general trend stands out for an increase in the frequency of mutant parasites, especially of $d h f r$ triple mutants and dhps double mutants. In 2000, the most common mutations found in STP were N51I (92\%) and S108N (95\%) for $d h f r$, and A437G (75\%) for dhps [21]. Our present results support a trend for fixation of the most common mutations at the $d h f r$ gene (96\% for both N51I and S108N). Regarding the dhps gene, the proportion of A437G mutations here reported $(81 \%)$ is also higher than in $2000(75 \%)$ but lower than in $2002(86 \%)$ [22]. In contrast, only $7 \%$ of $P$. falciparum isolates harboured the K540E mutation in 2000 [21] and none of the isolates carried this mutation in 2002 [22]. This could have been due to a smaller sample size or a more restricted geographic sampling area in the latter study. In the present dataset the frequency of the dhps $\mathrm{K} 540 \mathrm{E}$ was $11 \%$ ( $8 \%$ single $+3 \%$ mixed infections, Table 1) and there was an increase of the double dhps mutant A437G/K540E (2000: <7\%; 2004: 11\%), consequently leading to a 2-fold rise of the $d h f r+d h p s$ quintuple mutant (2000: 4\%; 2004: 9\%). The K540E mutation is only seldomly found in West Africa [13]. In contrast, in East Africa both the K540E allele and its associated quintuple mutant have reached high prevalence and have been shown to be robust predictors of SP clinical failure $[5,38,39]$. Therefore, SP remains partially effective in Central Africa possibly due to the still reduced frequency of the K540E mutation. The observed increase in the prevalence of the dhps K450E mutation and consequently of the quintuple mutant in STP should thus be considered a subject of concern.

In the present study, two distinct haplotypes were found associated with the double mutant N51I:S1018N and three were associated with the triple mutant N51I:C59R:S1018N. In the triple mutants, the most abundant haplotype, H5 (0.3 kb/4.4 kb/5.3 kb: 114 bp/183 $\mathrm{bp} / 210 \mathrm{bp}$ ), is an exact match of the haplotype of the $P$. falciparum K1 laboratory strain. This strain has a microsatellite profile that differs from the intercontinental widespread triple mutant haplotype of Southeast Asian origin (Roper C. pers. comm.). By reviewing the litera- 


\section{dhfr genotypes}

\begin{tabular}{|c|c|c|c|c|c|c|c|c|c|}
\hline & & $R_{s}$ & $H_{e}$ & $R_{s}$ & $H_{e}$ & $R_{s}$ & $H_{e}$ & $F_{S T}$ & $P$ \\
\hline \multirow[t]{4}{*}{ Loci flanking dhfr gene } & Dhfr 0.3 & 8 & 0.34 & 7 & 0.68 & 9 & 0.51 & 0.38 & $<0.0001$ \\
\hline & Dhfr 4.4 & 8 & 0.48 & 6 & 0.45 & 7 & 0.46 & -0.01 & NS \\
\hline & Dhfr 5.3 & 6 & 0.35 & 6 & 0.37 & 7 & 0.36 & 0.57 & $<0.0001$ \\
\hline & All loci & 7 & 0.39 & 6 & 0.50 & 8 & 0.44 & 0.37 & $<0.0001$ \\
\hline \multirow[t]{4}{*}{ Loci flanking dhps gene } & Dhps 0.8 & 12 & 0.67 & 10 & 0.53 & 13 & 0.60 & 0.01 & NS \\
\hline & Dhps 4.3 & 8 & 0.70 & 7 & 0.67 & 8 & 0.69 & 0.01 & NS \\
\hline & Dhps 7.7 & 14 & 0.92 & 15 & 0.90 & 17 & 0.91 & -0.01 & NS \\
\hline & All loci & 11 & 0.76 & 11 & 0.70 & 13 & 0.73 & 0.00 & NS \\
\hline \multirow[t]{5}{*}{ Neutral loci } & TAA81 & 8 & 0.83 & 11 & 0.84 & 10 & 0.83 & 0.02 & NS \\
\hline & TA109 & 10 & 0.76 & 11 & 0.72 & 11 & 0.74 & 0.01 & NS \\
\hline & TA87 & 11 & 0.89 & 12 & 0.85 & 12 & 0.87 & 0.01 & NS \\
\hline & PfPK2 & 10 & 0.85 & 13 & 0.88 & 13 & 0.87 & -0.01 & NS \\
\hline & All loci & 10 & 0.83 & 12 & 0.82 & 12 & 0.83 & 0.01 & NS \\
\hline
\end{tabular}

$N$ : Number of isolates genotyped. All loci: mean over loci $R_{s}$ and $H_{e}$ and global $F_{S T}$ over loci as calculated by FSTAT. $P$ : $P$-values of permutation tests to assess significance of $F_{S T}$ values. NS: non-significant $(P>0.05)$. In bold: significant after Bonferroni corrections for multiple tests.

ture, we found haplotypes very close to H5 in Senegal (113 bp/183 bp/211), [11]). In addition, haplotype H4 (108 bp/183 bp/210 bp), that occurred once in our sample, nearly matches the Senegalese haplotype (109 bp/183 $\mathrm{bp} / 211 \mathrm{bp}$ ) that was confirmed to be of Southeast Asian origin [11]. Haplotype H3 is likely to have derived from $\mathrm{H} 4$ by recombination or mutation as it differs only at the most distal microsatellite locus (5.3 kb). However, the H3 triple mutant may also have arise from $\mathrm{H} 2$ double mutants through an additional mutation occurring at position 59 of the $d h f r$ gene. Indeed, haplotype $\mathrm{H} 2$ shares the same microsatellite profile as $\mathrm{H} 3$ and it was the most frequent haplotype in double mutants. Taken together, it appears that $d h f r$ triple mutants in STP derive from two independent lineages that were introduced in the islands from continental Africa, although we cannot fully exclude one additional independent local origin associated with haplotype $\mathrm{H} 3$.

Similarly, microsatellite haplotype composition for the dhps gene provides evidence for at least three independent introductions of mutant parasites in STP. The only dhps double mutant haplotype identified has a microsatellite profile coincident with the SGE 1 lineage described by Pearce et al. [13]. This double mutant lineage has originated in East Africa where it is the most prevalent mutant lineage. In West Africa, the SGE 1 is rare but it has been detect in a few West African countries, including Gabon in the Gulf of Guinea [13]. In West Africa, A437G single mutants prevail and three independent ancestry lineages have been identified based on the two microsatellites most proximal to the dhps gene, $0.8 \mathrm{~kb}$ and $4.3 \mathrm{~kb}$ [13]. Using the same criterion, haplotypes $\mathrm{H} 1$, $\mathrm{H} 2$ and $\mathrm{H} 3$ can be considered as representatives of the AGK/SGK 1 lineage. This single mutant lineage is the most prevalent in central and Southwest Africa, including Angola, Congo and Gabon [13]. Haplotype H6 has a microsatellite profile closer to the AGK/SGK 3 lineage that displays highest frequencies in countries bordering the Gulf of Guinea such as Cameroon, Gabon, Ghana and Nigeria [13]. Therefore, the haplotype composition of dhps mutant parasites found in STP agrees with a scenario of parasite introduction from neighbouring countries of the Gulf of Guinea.

As reported for other $P$. falciparum populations in continental Africa $[10,13,17]$, the analysis of flanking microsatellites provided evidence of a selective sweep for both $d h f r$ and dhps resistant mutants. Reduced genetic diversity and increased genetic differentiation was observed at microsatellites flanking $d h f r$ and $d h p s$ when compared to neutral loci or when comparing resistant parasites with 
Table 5: Allele richness $\left(R_{s}\right)$, expected heterozygosity $\left(H_{e}\right)$ and $F_{S T}$ estimates at flanking and neutral microsatellites of $P$. falciparum dhps genotypes

\begin{tabular}{|c|c|c|c|c|c|c|c|c|c|c|c|}
\hline \multicolumn{2}{|l|}{ Microsatellites } & \multicolumn{2}{|c|}{ Wild type $(N=26)$} & \multicolumn{2}{|c|}{ Single mutant $(N=154)$} & \multicolumn{2}{|c|}{ Double mutant $(N=15)$} & \multicolumn{2}{|c|}{ all samples $(N=195)$} & \\
\hline & & $R_{s}$ & $H_{e}$ & $R_{s}$ & $H_{e}$ & $R_{s}$ & $H_{e}$ & $R_{s}$ & $H_{e}$ & $F_{S T}$ & $P$ \\
\hline \multirow[t]{4}{*}{ Loci flanking dhps gene } & Dhps 0.8 & 8 & 0.91 & 4 & 0.47 & 5 & 0.79 & 6 & 0.71 & 0.25 & $<0.0001$ \\
\hline & Dhps 4.3 & 6 & 0.85 & 4 & 0.53 & 3 & 0.26 & 4 & 0.55 & 0.30 & $<0.0001$ \\
\hline & Dhps 7.7 & 8 & 0.90 & 10 & 0.92 & 3 & 0.28 & 9 & 0.71 & 0.12 & 0.02 \\
\hline & Over all loci & 7 & 0.82 & 6 & 0.63 & 4 & 0.45 & 6 & 0.66 & 0.22 & $<0.0001$ \\
\hline \multirow[t]{4}{*}{ Loci flanking dhfr gene } & Dhfr 0.3 & 5 & 0.68 & 6 & 0.72 & 5 & 0.76 & 6 & 0.72 & 0.02 & NS \\
\hline & Dhfr 4.4 & 4 & 0.49 & 5 & 0.44 & 2 & 0.13 & 5 & 0.36 & $<-0.01$ & NS \\
\hline & Dhfr 5.3 & 5 & 0.66 & 5 & 0.63 & 3 & 0.53 & 5 & 0.61 & -0.01 & NS \\
\hline & Over all loci & 5 & 0.61 & 5 & 0.60 & 3 & 0.47 & 5 & 0.56 & 0.01 & NS \\
\hline \multirow[t]{5}{*}{ Neutral loci } & TAA81 & 7 & 0.84 & 7 & 0.83 & 6 & 0.83 & 7 & 0.83 & 0.01 & NS \\
\hline & TA109 & 6 & 0.74 & 8 & 0.77 & 4 & 0.50 & 8 & 0.67 & 0.01 & NS \\
\hline & TA87 & 9 & 0.87 & 9 & 0.87 & 7 & 0.87 & 9 & 0.87 & $<0.01$ & NS \\
\hline & PfPK2 & 7 & 0.85 & 10 & 0.88 & 6 & 0.86 & 10 & 0.86 & 0.01 & NS \\
\hline & Over all loci & 7 & 0.83 & 9 & 0.84 & 6 & 0.77 & 9 & 0.81 & 0.01 & NS \\
\hline
\end{tabular}


wild type ones in the case of dhps. In the latter, this was more evident for the case of double mutants. These data correlate well with the trend for an increase of dhps double mutants since 2000 [21], and consequently of $d h f r /$ dhps quintuple mutants.

Population structure could also contribute to the observed patterns of differentiation at flanking loci, particularly if one takes into account that this study analysed $P$. falciparum isolates from two islands. However, when the samples were grouped according to collection site, the $F_{S T}$ estimate obtained for neutral loci, albeit significant, was $c a$. two-fold lower than those observed for the microsatellites flanking $d h f r$ and $d h p s$ genes. Moreover, low and non-significant $F_{S T}$ values were obtained for all neutral microsatellites when samples were grouped according to their genotypes at both genes. It is therefore unlikely that the observed patterns of differentiation at flanking loci result mainly from population subdivision.

In a scenario of a selective sweep acting on recently introduced multiple haplotypes of a mutation under selection (i.e. soft sweeps) one expects a strong LD signal [40]. This is because introduced beneficial mutants carrying new haplotypes cause the polymorphic sites to be in complete LD. Unexpectedly, LD tests provided only weak evidence of increased linkage, with a single significant test for a locus pair at $d h f r$ double mutants and another for dhps single mutants. This observation may be attributed to the fact that SP-resistance in STP has been prevalent for quite sometime and, consequently, LD around these loci has decayed over time due to the accumulation of mutations and also to the effect of recombination between haplotypes [40]. In STP, the first report of therapeutic failure to SP dates from 2000 [21], but positive selection of mutant $d h f r$ and dhps through drug pressure most likely pre-dates this first finding. Being the $2^{\text {nd }}$ line for malaria treatment, one expects an increased usage of SP since the early-1990's, when considerable levels of resistance to the $1^{\text {st }}$ line chloroquine had already been reported [19]. Altogether these data point to an early introduction of mutant parasites in STP, possibly during the first half of the 1990's, which were subjected to selective pressure due to an already on-going increase of SP usage in the islands. Presence of the $d h f r$ triple mutant in Cameroon was reported for the first time in 1985 [9]. The emergence of dhps mutants is considered to be more recent, but previous reports suggest that the emergence of all mutant lineages, including the single mutants of West African origin, may have occurred in the early- to mid-1990's (see [13] and refs. therein). These time-scales are in accordance with that here proposed for the introduction mutant parasites in STP.

\section{Conclusions}

In spite of its geographical isolation, resistance to SP in $P$. falciparum populations of STP islands has emerged from multiple introductions of mutant parasites from the continent, possibly of West African origin. Once introduced in the islands, resistance associated mutants have been subjected to positive selection, resulting in a selective sweep detectable at flanking microsatellites, due to the increased usage of SP. As a consequence, it took little more than a decade for resistant parasites to reach near fixation frequencies. These findings reinforce the crucial role of gene flow and strong selective pressures in the rapid establishment of resistance to SP in $P$. falciparum populations. They also highlight the importance of human migration in the spread of drug resistant malaria parasites, as the distance between islands and continent should render mosquito-mediated parasite dispersal unrealistic. Since 2004, a new ACT-based malaria treatment regime was implemented in STP. The previous experience with SP here reported makes a strong case for a continuous monitoring of parasite susceptibility levels, with particular focus on migrants and travellers from endemic areas.

\section{Competing interests \\ The authors declare that they have no competing interests.}

\section{Authors' contributions}

PS, AG, JLV and VT carried out the molecular analyses. PS and VT performed the genetic data analysis. PS, JP and PC drafted the manuscript. JP, PC and VER conceived the study. CF carried out blood sample collections. All authors read and approved the final manuscript.

\section{Acknowledgements}

To the people of São Tomé and Príncipe that volunteered to participate in the study. To the entomology team of CNE, STP for the field support. To Dr. Cally Roper (LSHTM, UK) and Dr. Vilfrido Gil (UNDP, STP) for the valuable comments and suggestions given to this work. This research was funded by Fundação para a Ciência e Tecnologia/FEDER (POCI/SAU-ESP/56903/2004 and PPCDT/ SAU-ESP/56903/2004) and Instituto Português de Apoio ao Desenvolvimento/ Ministério dos Negócios Estrangeiros, Portugal. PS was supported by a Postdoctoral grant (SFRH/BPD/34395/2006) from Fundação para a Ciência e Tecnologia.

\section{Author Details}

1UEI Malária \& UEl Biologia Molecular, Centro de Malária e outras Doenças Tropicais, Instituto de Higiene e Medicina Tropical, Universidade Nova de Lisboa. Rua da Junqueira 100, 1349-008 Lisboa, Portugal and ${ }^{2}$ Centro Nacional de Endemias, Ministério da Saúde. Caixa Postal 218, São Tomé, República Democrática de São Tomé e Príncipe

Received: 29 January 2010 Accepted: 9 June 2010 Published: 9 June 2010

\section{References}

1. Noedl H, Se Y, Schaecher K, Smith BL, Socheat D, Fukuda MM, Artemisinin Resistance in Cambodia 1 Study Consortium: Evidence of ArtemisininResistant Malaria in Western Cambodia. N Engl J Med 2008, 359:2619-2620.

2. Peterson D, Walliker D, Wellems T: Evidence that a point mutation in dihydrofolate reductase-thymidylate synthase confers resistance to pyrimethamine in falciparum malaria. Proc Natl Acad Sci USA 1988 85:9114. 
3. Brooks D, Wang P, Read M, Watkins W, Sims P, Hyde J: Sequence variation of the hydroxymethyldihydropterin pyrophosphokinase: dihydropteroate synthase gene in lines of the human malaria parasite, Plasmodium falciparum, with differing resistance to sulfadoxine. Eur J Biochem 1994, 224:397-405.

4. Kublin J, Dzinjalamala F, Kamwendo D, Malkin E, Cortese J: Molecular markers for failure of sulfadoxine-pyrimethamine and chlorproguanildapsone treatment of Plasmodium falciparum malaria. J Infect Dis 2002, 185:380-388.

5. Aponte JJ, Schellenberg D, Egan A, Breckenridge A, Carneiro I, Critchley J, Danquah I, Dodoo A, Kobbe R, Lell B, May J, Premji Z, Sanz S, Sevene E, Soulaymani-Becheikh R, Winstanley P, Adjei S, Anemana S, Chandramohan D, Issifou S, Mockenhaupt F, Owusu-Agyei S, Greenwood B, Grobusch MP, Kremsner PG, Macete E, Mshinda H, Newman RD, Slutsker $L$, Tanner M, et al:: Efficacy and safety of intermittent preventive treatment with sulfadoxine-pyrimethamine for malaria in African infants: a pooled analysis of six randomised, placebo-controlled trials. Lancet 2009, 374:1533-1542.

6. Mermin J, Bunnell R, Lule J, Opio A, Gibbons A, Dybul M: Developing an evidence-based, preventive care package for persons with HIV in Africa. Trop Med Int Health 2005, 10:961-970.

7. Roper C, Pearce R, Nair S, Sharp B, Nosten F, Anderson T: Intercontinental spread of pyrimethamine-resistant malaria. Science 2004, 305:1124.

8. McCollum AM, Poe AC, Hamel M, Huber C, Zhou Z, Shi YP, Ouma P, Vulule J, Bloland P, Slutsker L, Barnwell JW, Udhayakumar V, Escalante AA: Antifolate resistance in Plasmodium falciparum: multiple origins and identification of novel dhfr alleles. J Infect Dis 2006, 194:189-197.

9. Maïga O, Djimdé AA, Hubert V, Renard E, Aubouy A, Kironde F, Nsimba B, Koram K, Doumbo OK, Le Bras J, Clain J: A shared Asian origin of the triple-mutant $d$ hfr allele in Plasmodium falciparum from sites across Africa. J Infect Dis 2007, 196:165-172.

10. McCollum AM, Basco LK, Tahar R, Udhayakumar V, Escalante AA: Hitchhiking and selective sweeps of Plasmodium falciparum sulfadoxine and pyrimethamine resistant alleles in a population from central Africa. Antimicrob Agents Chemother 2008, 52:4089-4097.

11. Ndiaye D, Daily JP, Sarr O, Ndir O, Gaye O, Mboup S, Roper C, Wirth DF: Defining the origin of Plasmodium falciparum resistant $d h f r$ isolates in Senegal. Acta Trop 2006, 99:106-111.

12. Mita T, Tanabe K, Takahashi N, Culleton R, Ndounga M, Dzodzomenyo M, Akhwale WS, Kaneko A, Kobayakawa T: Indigenous evolution of Plasmodium falciparum pyrimethamine resistance multiple times in Africa. J Antimicrob Chemother 2009, 63:252-255.

13. Pearce RJ, Pota H, Evehe MS, Bâ el-H, Mombo-Ngoma G, Malisa AL, Ord R, Inojosa W, Matondo A, Diallo DA, Mbacham W, van den Broek IV, Swarthout TD, Getachew A, Dejene S, Grobusch MP, Njie F, Dunyo S, Kweku M, Owusu-Agyei S, Chandramohan D, Bonnet M, Guthmann JP, Clarke S, Barnes KI, Streat E, Katokele ST, Uusiku P, Agboghoroma CO, Elegba OY, et al:: Multiple origins and regional dispersal of resistant dhps in African Plasmodium falciparum malaria. PLoS Med 2009, 6:e1000055.

14. Hawkins VN, Auliff A, Prajapati SK, Rungsihirunrat K, Hapuarachchi HC, Maestre A, O'Neil MT, Cheng Q, Joshi H, Na-Bangchang K, Sibley CH: Multiple origins of resistance-conferring mutations in Plasmodium vivax dihydrofolate reductase. Malar J 2008, 7:72.

15. Wiehe T: The effect of selective sweeps on the variance of the allele distribution of a linked multiallele locus: hitchhiking of microsatellites. Theor Popul Biol 1998, 53:272-283.

16. Nair S, Williams JT, Brockman A, Paiphun L, Mayxay M, Newton PN, Guthmann JP, Smithuis FM, Hien TT, White NJ, Nosten F, Anderson TJ: A selective sweep driven by pyrimethamine treatment in southeast Asian malaria parasites. Mol Biol Evol 2003, 20:1526-1536.

17. Pearce R, Malisa A, Kachur SP, Barnes K, Sharp B, Roper C: Reduced variation around drug-resistant $d h f r$ alleles in African Plasmodium falciparum. Mol Biol Evol 2005, 22:1834-1844.

18. McCollum AM, Mueller K, Villegas L, Udhayakumar V, Escalante AA Common origin and fixation of Plasmodium falciparum dhfr and dhps mutations associated with sulphadoxine-pyrimethamine resistance in a low transmission area in South America. Antimicrob Agents Chemother 2007, 51:2085-2091.

19. Martet G, Da Conceicao S, Cordoliani G, Delolme H, Raphenon G, Hovette P, Doury JC, Baudon D, Touze JE, Lecamus JL: Malaria in the republic of
São Tomé and Principe. Epidemiologic evaluation and chemoresistance of P. falciparum. Bull Soc Pathol Exot 1991, 84:273-280.

20. Lopes D, Nogueira F, Ferreira C, Gil JP, do Rosário VE, Cravo P: Pfcrt and pfmdr 1 mutations and chloroquine resistance in Plasmodium falciparum from São Tomé and Príncipe, West Africa. Ann Trop Med Parasitol 2002, 96:831-834.

21. Cravo P, Figueiredo S, Nogueira F, Lopes D, Ferreira I, Ferreira C, Gil J, Rosario VE: High frequency of the genetic polymorphisms associated with sulfadoxine-pyrimethamine resistance, among Plasmodium falciparum isolates from Sao Tome and Principe, West Africa. Ann Trop Med Parasitol 2004, 98:293-296.

22. Tahar R, Djaman J, Ferreira C, Basco L: Surveillance de la résistance de Plasmodium falciparum à la sulfadoxine-pyriméthamine par le test moléculaire à São Tomé et Príncipe. Bull Soc Pathol Exot 2007, 100:115-118.

23. Teklehaimanot HD, Teklehaimanot A, Kiszewski A, Rampao HS, Sachs JD: Malaria in Sao Tome and Principe: on the brink of elimination after three years of effective antimalarial measures. Am J Trop Med Hyg 2009, 80:133-140

24. Pinto J, Sousa CA, Gil V, Ferreira C, Goncalves L, Lopes D, Petrarca V, Charlwood JD, do Rosario VE: Malaria in Sao Tome and Principe: parasite prevalences and vector densities. Acta Trop 2000, 76:185-193.

25. Plowe C, Djimde A, Bouare M, Doumbo O, Wellems T: Pyrimethamine and proguanil resistance-conferring mutations in Plasmodium falciparum dihydrofolate reductase: polymerase chain reaction methods for surveillance in Africa. Am J Trop Med Hyg 1995, 52:565-568.

26. Snounou G, Viriyakosol S, Zhu X, Jarra W, Pinheiro L, do Rosario V, Thaithong S, Brown K: High sensitivity of detection of human malaria parasites by the use of nested polymerase chain reaction. Mol Biochem Parasitol 1993, 61:315-320

27. Duraisingh MT, Curtis J, Warhurst DC: Plasmodium falciparum: detection of polymorphisms in the dihydrofolate reductase and dihydropteroate synthetase genes by PCR and restriction digestion. Exp Parasitol 1998, 89:1-8.

28. Roper C, Pearce R, Bredenkamp B, Gumede J, Drakeley C, Mosha F, Chandramohan D, Sharp B: Antifolate antimalarial resistance in southeast Africa: a population-based analysis. Lancet 2003, 361:1174-1181

29. Anderson T, Su Xz, Bockarie M, Lagog M, Day KP: Twelve microsatellite markers for characterization of Plasmodium falciparum from fingerprick blood samples. Parasitol 1999, 119:113-125.

30. Conway DJ, Machado RLD, Singh B, Dessert P, Mikes ZS, Povoa MM, Oduola AMJ, Roper C: Extreme geographical fixation of variation in the Plasmodium falciparum gamete surface protein gene Pfs $48 / 45$ compared with microsatellite loci. Mol Biochem Parasitol 2001, 115:145-156.

31. Goudet J: FSTAT (version 1.2): A program to estimate and test gene diversities and fixation indices. J Hered 2002, 86:485-486.

32. Park SDE: Trypanotolerance in West African cattle and the population genetic effects of selection. PhD thesis; University of Dublin 2001.

33. Anderson TJ, Haubold B, Williams JT, Estrada-Franco JG, Richardson L, Mollinedo R, Bockarie M, Mokili J, Mharakurwa S, French N, Whitworth J, Velez ID, Brockman AH, Nosten F, Ferreira MU, Day KP: Microsatellite markers reveal a spectrum of population structures in the malaria parasite Plasmodium falciparum. Mol Biol Evol 2000, 17:1467-1482.

34. Weir B, Cockerham C: Estimating F-statistics for the analysis of population structure. Evolution 1984, 38:1358-1370.

35. Raymond M, Rousset F: GENEPOP (version 1.2): population genetics software for exact tests and ecumenicism. J Hered 1995, 86:248-249.

36. Holm S: A simple sequentially rejective multiple test procedure. Scand J Statistics 1979, 6:65-70.

37. Escalante AA, Cornejo OE, Rojas A, Udhayakumar V, Lal AA: Assessing the effect of natural selection in malaria parasites. Trends Parasitol 2004, 20:388-395.

38. Bwijo B, Kaneko A, Takechi M, Zungu IL, Moriyama Y, Lum JK, Tsukahara T, Mita T, Takahashi N, Bergqvist Y, Björkman A, Kobayakawa T: High prevalence of quintuple mutant $\mathrm{dhps} / \mathrm{dhfr}$ genes in Plasmodium falciparum infections seven years after introduction of sulfadoxine and pyrimethamine as first line treatment in Malawi. Acta Trop 2003, 85:363-373.

39. Dorsey G, Dokomajilar C, Kiggundu M, Staedke SG, Kamya MR, Rosentha PJ: Principal role of dihydropteroate synthase mutations in mediating 
resistance to sulfadoxine-pyrimethamine in single-drug and combination therapy of uncomplicated malaria in Uganda. Am J Trop Med Hyg 2004, 71:758-763.

40. Pennings PS, Hermisson J: Soft sweeps III: The signature of positive selection from recurrent mutation. PloS Genet 2:e186.

\section{Pre-publication history}

The pre-publication history for this paper can be accessed here: http://www.biomedcentral.com/1471-2334/10/163/prepub

doi: 10.1186/1471-2334-10-163

Cite this article as: Salgueiro et al., Tracing the origins and signatures of selection of antifolate resistance in island populations of Plasmodium falciparum BMC Infectious Diseases 2010, 10:163

Submit your next manuscript to BioMed Central and take full advantage of:

- Convenient online submission

- Thorough peer review

- No space constraints or color figure charges

- Immediate publication on acceptance

- Inclusion in PubMed, CAS, Scopus and Google Scholar

- Research which is freely available for redistribution

Submit your manuscript at www.biomedcentral.com/submit 